\title{
Maintenance of adult mouse type A spermatogonia in vitro: influence of serum and growth factors and comparison with prepubertal spermatogonial cell culture
}

\author{
L. B. Creemers ${ }^{1}$, K. den Ouden ${ }^{1}$, A. M. M. van Pelt ${ }^{1}$ \\ and D. G. de Rooij ${ }^{1,2}$ \\ ${ }^{1}$ Department of Endocrinology, Faculty of Biology, University of Utrecht, Padualaan 8, \\ 3584 CH Utrecht, The Netherlands; and ${ }^{2}$ Department of Cell Biology, Academic Medical \\ Centre Utrecht, Heidelberglaan 100, 3584 CX Utrecht, The Netherlands
}

The culture of spermatogonial cells under well-defined conditions would be an important method for elucidating the mechanisms involved in spermatogenesis and in establishing tissue regeneration in vivo. In this study, a serum-free culture system was established, with type A spermatogonia isolated from adult vitamin A-deficient mice. At days 1, 3 and 7 of culture, the viability and proliferation of cells were monitored. The viability of the cells decreased by day 7 to $10 \%$ of the cells present. Proliferation occurred mainly during day 1 , when $1 \%$ of the germ cells was proliferating. Co-labelling for a germ cell marker (heat shock protein-90 $\alpha$, Hsp90 $\alpha$ ), and a marker used to detect dividing cells (bromodeoxyuridine, BrdU), showed that this proliferation was restricted to germ cells. In an attempt to improve these parameters, medium containing fetal calf serum (FCS) was used. Viability was not influ-

\section{Introduction}

Spermatogenesis is a complex and tightly regulated process during which successive mitotic and meiotic divisions finally lead to the production of differentiated spermatozoa (Huckins, 1971; Oakberg, 1971). At the basis of this process are the spermatogonial stem cells, capable of maintaining their number as well as generating differentiating cells. Because of this pivotal role, viable systems for proliferation of spermatogonial stem cells under well-defined culture conditions would be an important tool in spermatogenesis research as well as a therapeutic method for regeneration and repair of impaired spermatogenesis.

One of the major setbacks in spermatogonial stem cell research is the lack of specific markers for this type of cell. As a consequence, stem cells cannot be identified as such during culture; moreover, it is impossible to obtain pure cultures. Until now, the most common way of increasing the stem cell content of isolated germ cell suspensions is to use neonatal or prepubertal testes, in which spermatogenesis is

Email: I.b.creemers@bio.uu.nl enced by serum, but proliferation was markedly enhanced. However, after day 7 of incubation with FCS, co-immunolocalization for Hsp90 $\alpha$ and BrdU showed a preferential proliferation of somatic cells. Comparison of cultures of adult cells with cultures of prepubertal germ cells, commonly used in studies of spermatogenesis, showed that prepubertal germ cells are twice as viable. In addition, a different proliferation profile was observed, with a peak at day 3. Here, a distinct proliferation of somatic cells was also noted. The results from the present study indicate that the origin of isolated germ cells partly determines culture outcome and that cultures of prepubertal germ cells may not be representative for adult spermatogenesis. Moreover, adding FCS to the culture medium invokes the risk of profound and undesirable effects on cell composition, also underlining the need for identification of germ cells during culture. at an early stage and thus fewer contaminating differentiated germ cells are present.

In these germ cell culture systems, viability generally decreases to 20-30\% within 1 week (Morena et al., 1996; Dirami et al., 1999; Sugiyama et al., 2001). The addition of serum (Maekawa and Nishimune, 1991; Morena, et al., 1996; Nagano et al., 1998; Sugiyama et al., 2001; van der Wee et al., 2001) and the maintenance of germ cells on feeder layers (Tres and Kierszenbaum, 1983; Nagano et al., 1998; Tres and Kierszenbaum, 1999; Sugiyama et al., 2001; van der Wee et al., 2001) have been applied in attempts to improve viability. A combination of granulocytemacrophage colony-stimulating factor (GM-CSF) and stem cell factor (SCF) was found to yield a moderate improvement of spermatogonial viability under serum-free culture conditions (Dirami et al., 1999), but otherwise few data are available on the use of growth factors. In addition, the use of a special culture medium, potassium-rich medium developed according to the simplex optimization method (KSOM), improved survival (Dirami et al., 1999). Proliferation of spermatogonia under culture conditions has been investigated in a small number of studies only. Tritiated thymidine incorporation has been demonstrated, 
though not quantitated, in cultures of prepubertal rat germ cells (Tres and Kierszenbaum, 1983), and in neonatal mouse germ cell cultures, proliferation during the first three days was determined to occur in a small fraction of the germ cells (Maekawa and Nishimune, 1991). During culture, identification of germ cells (Tres and Kierszenbaum, 1983; Sugiyama et al., 2001; van der Wee et al., 2001) has been achieved either using morphological characteristics (Tres and Kierszenbaum, 1983), or biochemical markers. These markers are c-kit (Morena, et al., 1996; van der Wee et al., 2001), a protein produced by differentiating germ cells and Leydig cells (Manova et al., 1990; Dym et al., 1995; Sandlow et al., 1996), and two, as yet unidentified, antigens present on the cell surface of all germ cells and spermatogonial cells only, respectively (Sugiyama et al., 2001).

With one exception, all of the studies mentioned above were based on the culture of germ cells isolated from prepubertal or neonatal animals. However, there are indications that the first spermatogenic wave differs from all subsequent spermatogenic cycles (Kluin et al., 1982; van Haaster and de Rooij, 1993). Therefore, behaviour of adult spermatogonia in culture may also differ from that of prepubertal spermatogonia, which, for example, would have consequences for infertile adult males. Moreover, until now, viability, proliferation and germ cell identity have never been monitored simultaneously during culture. In the present study, the maintenance in vitro of mouse spermatogonia isolated from adult animals fed a vitamin-A deficient diet is described. In these animals, spermatogenesis is arrested at an early stage of the spermatogenic cycle (van Pelt et al., 1995), resulting in a suspension of type A spermatogonia of which about $10 \%$ consists of spermatogonial stem cells, normally comprising only $0.03 \%$ of the testicular germ cell population (Tegelenbosch and de Rooij, 1993). Viability and proliferation under different culture conditions were monitored and a comparison was made with cultured prepubertal germ cells to determine whether these would respond similarly to culture conditions. Identification of germ cells during culture was based on the use of a germ cell-specific marker, Hsp90 $\alpha$ (Lee, 1990).

\section{Materials and Methods}

Acetylated bovine serum albumin $\left(\mathrm{BSA}_{\mathrm{C}}\right)$, normal goat serum (NGS) and normal rabbit serum (NRS) were from Aurion (Wageningen); minimal essential medium (MEM), FCS, penicillin, streptomycin, single strength nonessential amino acids, gentamycin, Hepes and potassium-rich medium, developed according to the simplex optimization method (KSOM) (Erbach et al., 1994), from Gibco (Life Technologies, Paisley). Rabbit polyclonal antibody against Hsp90 $\alpha$ was purchased from Stressgen Biotechnologies Corp (Victoria), mouse-anti-bromodeoxyuridine (BrdU) from Becton Dickinson (San Jose, CA) and fluorescein isothiocyanate (FITC)-labelled goat-anti-rabbit and Texas red (TR)-labelled goat-anti-mouse antibodies were obtained from Jackson (West Grove, PA). Vectashield was from Vector Laboratories (Burlingame, CA). Culture plates, 384 or 60 wells, and 16-well glass chamber slides were from Nunc (Life Technologies, Roskilde), sodium bicarbonate, L-glutamine, human recombinant leukaemia inhibitory factor (LIF), basic fibroblast growth factor (bFGF), forskolin, transforming growth factor $\beta$ (TGF- $\beta$ ) and human recombinant platelet-derived growth factor (PDGF) were provided by Sigma (St Louis, MO). Granulocyte-macrophage colonystimulating factor (GM-CSF) and tumour necrosis factor $\alpha$ (TNF- $\alpha$ ) were from Bachem (Bubendorf), stem cell factor (SCF) from R\&D Systems inc (Minneapolis, MN) and glial cell-line-derived neurotrophic factor (GDNF) from PeproTech (Rocky Hill, NJ). Cells were cultured on growth factorreduced Matrigel from Becton Dickinson (San Jose, CA).

\section{Animals}

For all animal experiments, Nc/CpbU mice were used, a strain bred at the Laboratory Animal Facilities, Utrecht. Pregnant $\mathrm{Nc} / \mathrm{CpbU}$ mice were fed a vitamin A-deficient (VAD) diet (Teklad Trucking, Madison, WI) (van Pelt et al., 1995). Male offspring received the same diet and were used for the experiments at about 16 weeks; signs of vitamin A depletion were noted, including eye and coat disorders and a wobbly gait. Adult animals were killed by $\mathrm{CO}_{2}$ asphyxiation and their testes removed for the isolation of type $A$ spermatogonia. Nc/CpbU mice aged 8 days, born from mice maintained under standard conditions, were decapitated and used as donors for isolation of prepubertal germ cells.

All animal experiments were approved of and carried out according to regulations provided by the Animal Ethical Committee of the University Medical Centre Utrecht.

\section{Isolation and culture of spermatogonia}

Isolation of adult type A spermatogonia was carried out essentially as described by Schrans-Stassen et al. (1999). Testes were decapsulated and after teasing apart the tubule fragments, they were subjected to two successive enzymatic treatments ( $1 \mathrm{mg}$ each enzyme $\mathrm{ml}^{-1}$ of MEM for $20 \mathrm{~min}$ and $45 \mathrm{~min}$, respectively): the first treatment was with trypsin, hyaluronidase and collagenase; the second treatment was with hyaluronidase and collagenase alone. For prepubertal cell isolations, the first incubation with enzymes was reduced to $5 \mathrm{~min}$ and took place with $0.5 \mathrm{mg}$ each enzyme $\mathrm{ml}^{-1}$. Cells were separated from remaining tubule fragments by centrifugation at $30 \mathrm{~g}$ for $2 \mathrm{~min}$ and, after filtration through 77 and $55 \mu \mathrm{m}$ nylon filters, separated further on a Percoll discontinuous density gradient. Nomarski optics was used to assess the purity of fractions. Cells with a high nucleus:cytoplasm ratio and one or more distinct nucleoli (Fig. 1) were scored as type A spermatogonia (As to A4); the most common contaminations were Leydig cells and peritubular cells. In prepubertal cell suspensions, contamination consisted mainly of intermediate and type B spermatogonia and a small number of somatic cells. Fractions 

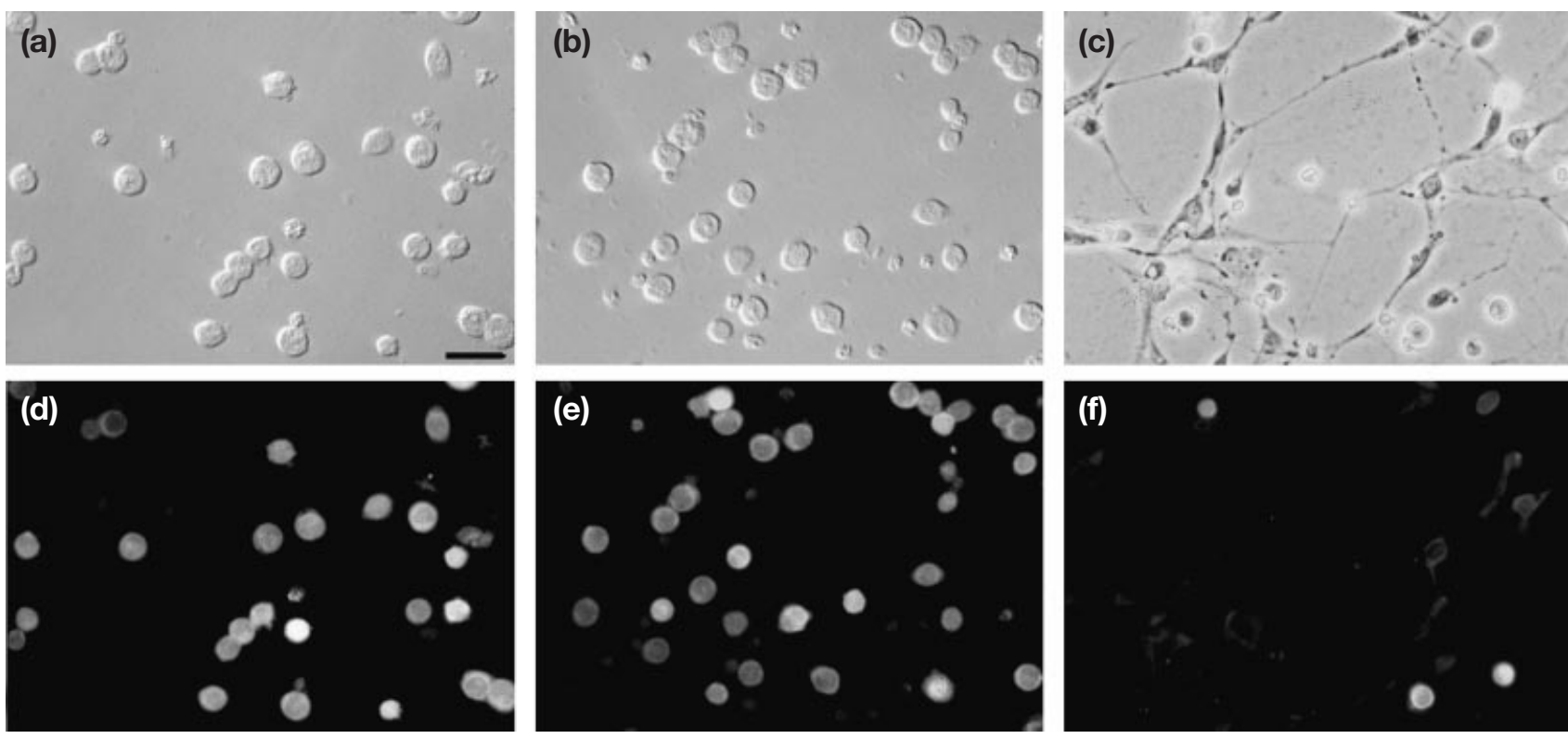

Fig. 1. Morphology and arrangement of mouse isolated spermatogonial suspensions at (a,d) day 1, (b,e) day 3 and (c,f) day 7 of culture. $(d-f)$ Heat shock protein-90 $\alpha(\mathrm{Hsp} 90 \alpha)$ labelling of germ cells shown by corresponding images $(\mathrm{a}, \mathrm{b})$ in differential interference contrast and (c) in phase-contrast, which was used for visualizing both round and flattened cells at day 7 . Scale bar represents $5 \mu \mathrm{m}$.

with sufficiently high purity were washed, counted and plated at $12 \times 10^{2}$ cells $\mathrm{mm}^{-2}$ in $\mathrm{KSOM}$ containing $100 \mathrm{iu}$ penicillin $\mathrm{ml}^{-1}-100 \mu \mathrm{g}$ streptomycin $\mathrm{ml}^{-1}, 1 \mathrm{ng} \mathrm{ml}^{-1}$ PDGF, bFGF, LIF and forskolin (basic growth factor mix) or MEM or KSOM containing $2.5 \%$ FCS. In addition, the effects of various other growth factors, added to the basic growth factor mix in KSOM, were studied: 2 or $20 \mathrm{ng}$ TNF- $\alpha \mathrm{ml}^{-1}$,

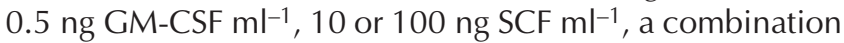

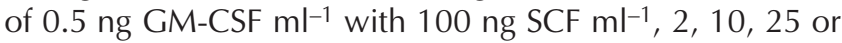
$100 \mathrm{ng}$ GDNF ml-1 and GDNF combined with TGF- $\beta$ (each at 2, 10 or $25 \mathrm{ng} \mathrm{ml}^{-1}$ ) were added to the culture medium. Cells were cultured for 1,3 or 7 days at $32^{\circ} \mathrm{C}$ in a humidified incubator under $5 \% \mathrm{CO}_{2}$, in wells that had been coated with a film of 1:10 diluted growth factor-reduced Matrigel. At these time points, cells were harvested and either viability was determined or cells were incubated in the presence of $\mathrm{BrdU}$ and fixed for immunolocalization of either $\mathrm{Hsp} 90 \alpha$ or BrdU; some immunolocalizations were double labellings for both markers.

For adult germ cell cultures, only data from cultures that started from isolated cell suspensions of at least $70 \%$ purity were described, except for determination of the correlation of viability at day 3 of culture with initial purity, which included experiments with suspensions of germ cells of $50 \%$ initial purity and higher. For cultures of prepubertal germ cells, only the results based on initial cell suspensions of at least $60 \%$ pure type $A$ spermatogonia have been included.

\section{Viability}

Viability of cultured cells was assessed by determining the percentage of cells excluding vital dye, using $70 \mu \mathrm{g}$
Trypan blue $\mathrm{ml}^{-1}$ or the Live and Dead kit according to the manufacturer's protocols (Molecular Probes, Leiden).

\section{BrdU incorporation}

Proliferative activity of cultured spermatogonia was determined by adding $0.1 \mathrm{mmol} \mathrm{BrdU}^{-1}$ of the culture medium (final concentration). Cells were then cultured for another $2.5 \mathrm{~h}$ before fixation. Co-immunolocalization of $\mathrm{BrdU}$ and $\mathrm{Hsp} 90 \alpha$ was performed as described below.

\section{Immunocytochemistry}

Cultured cells were fixed for $15 \mathrm{~min}$ in $80 \%$ methanol at $-20^{\circ} \mathrm{C}$. All subsequent incubation steps and washes were in Tris-buffered saline (TBS; $50 \mathrm{mmol}$ Tris $\mathrm{I}^{-1}, 150 \mathrm{mmol} \mathrm{NaCl}$ $\mathrm{I}^{-1}, \mathrm{pH}$ 7.6). Cells were permeabilized in $0.2 \%$ Triton and, for co-localization with $\mathrm{BrdU}$, exposed to $1 \%$ periodic acid for $1 \mathrm{~h}$ at $60^{\circ} \mathrm{C}$. Non-specific binding was blocked by incubating the cells for $30 \mathrm{~min}$ in the presence of $1 \% \mathrm{BSA}_{\mathrm{C}}$ and $10 \%$ normal goat serum. Incubation, either with rabbit-anti$\mathrm{Hsp} 90 \alpha$ at 1:250 or mouse-anti-BrdU at 1:80, or with both antibodies together, was carried out overnight at room temperature. Subsequently, cells were incubated for $1 \mathrm{~h}$ at room temperature, respectively, either with goat-anti-rabbit conjugated to FITC or goat-anti-mouse conjugated to TR, or with both secondary antibodies together, each at 1:150 in $1 \% \mathrm{BSA}_{c}$. Slides and 384-well plates were covered with Vectashield and evaluated under a Nikon inverted light microscope equipped with an epifluorescence mercury lamp. Micrographs were made using Kodak Ektachrome EL 400 ASA film.

Cell cultures in 384-well plates were subsequently evaluated for proliferation by counting the total number of 
cells per well that were positive for $\mathrm{Hsp} 90 \alpha$ or BrdU. The extent of proliferation of germ cells was expressed as the percentage of Hsp90 $\alpha$-positive cells that also labelled for BrdU. Somatic cell proliferation is given as the percentage of BrdU-positive cells that are Hsp90 $\mathrm{H}$-negative. Data are representative for two experiments.

\section{Statistical analysis}

Data are presented as means \pm SEM. Experiments were performed with five to ten data points per parameter. Statistical analysis was performed by Mann-Whitney or non-parametric ANOVA and subsequent Dunn's multiple comparisons test. A value of $P<0.05$ (two-tailed) was assumed to indicate statistical significance.

\section{Results}

\section{Culture of spermatogonia isolated from adult vitamin} A-deficient mice

Culture systems for spermatogonia isolated from VAD animals and cultured in KSOM including the basic mix of four growth factors, henceforth referred to as $\mathrm{KSOM}+$, were subject to various changes. At day 1 of culture, cells were spread evenly over the surface, and in general were of similar morphology: large, round to slightly triangular cells, most of them labelling with the general germ cell marker Hsp90 $\alpha$ (Fig. 1a,b,d,e). During the following days, the number of cells decreased and the remaining cells appeared to aggregate. At day 7 a heterogeneous cell morphology was observed, in which the germ cells usually were smaller, round cells, and seemed to group around cells with long cytoplasmic extensions (Fig. 1c,f).

\section{Viability of isolated adult spermatogonia during culture}

Immediately after isolation, the viability of the cells, as assessed by exclusion of vital dye, was $88 \pm 4 \%$ (mean \pm SEM, $n=5$ experiments). After day 1 of culture in $\mathrm{KSOM}+$, the viability of the cells decreased to $70 \pm 5 \%$ ( $n=5$ experiments) and to $19 \pm 2 \%(n=12$ experiments $)$ and $10 \pm 1 \%$ ( $n=7$ experiments) at days 3 and 7 , respectively (Fig. 2). Addition of GM-CSF, SCF or a combination of these growth factors, TNF- $\alpha$, Flt3 ligand or GDNF with or without TGF- $\beta$ did not significantly influence viability (data not shown).

\section{Association of viability with initial purity}

As contamination with somatic cells in the initial cell suspensions may have provided an advantage for the germ cells once in culture, we determined whether the viability was dependent on the purity of the initial cell suspensions, taking day 3 of culture as reference. No correlation was found between the initial purity and viability at day 3 (Fig. 3).

\section{Proliferation}

Proliferation of cells was mainly restricted to day 1 of culture, accounting for $0.8 \pm 0.2 \%$ ( $n=4$ experiments $)$ of

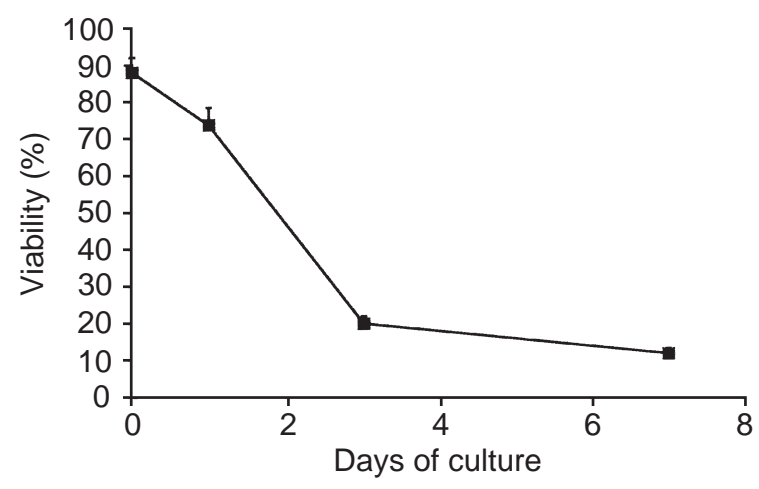

Fig. 2. Percentage of viable cells during culture of spermatogonia isolated from adult vitamin A-deficient mice, showing a pronounced decrease of viability after day 3 .

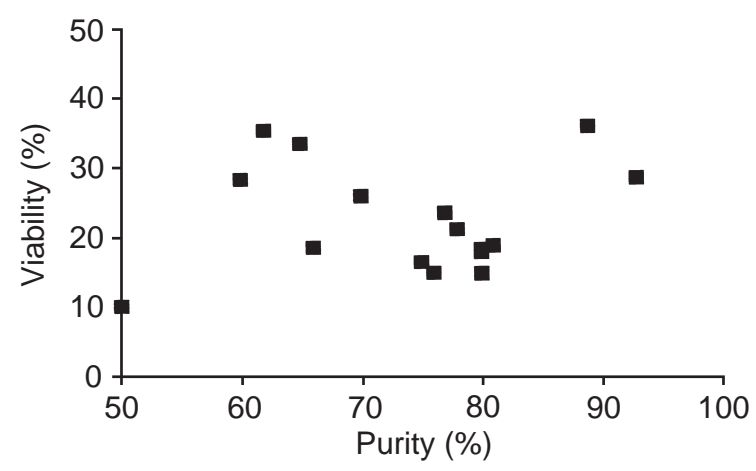

Fig. 3. Plot of purity of mouse spermatogonial suspensions at day 0 versus cell viability at day 3 of culture. No clear correlation is evident.

the cell population. All cells labelled at these time points were germ cells, as demonstrated by co-localization with Hsp90 $\alpha$ (Fig. 4). After days 3 and 7, in some experiments no proliferating cells were found at all, whereas in some cultures occasionally a labelled somatic cell was found, accounting for $<0.05 \%$ of the cells or $<1$ cell per well.

\section{Effects of medium containing serum on cell viability}

As viability of cells decreased during culture in $\mathrm{KSOM}+$, we verified whether FCS could improve cell survival. The effect of MEM containing 2.5\% FCS on viability of cells was evaluated, as this was found to provide optimal viability in culturing prepubertal bull spermatogenic cells (F. Izadyar, unpublished), in addition to KSOM containing 2.5\% FCS.

Upon comparison of the viability of cells in $\mathrm{KSOM}+$ versus KSOM or MEM with $2.5 \%$ FCS, no significant increase in the percentage of viable cells was found. In two of the four experiments performed with these culture media, viability after days 3 and 7 was even significantly lower in medium containing serum compared with medium containing KSOM+ (Fig. 5). 


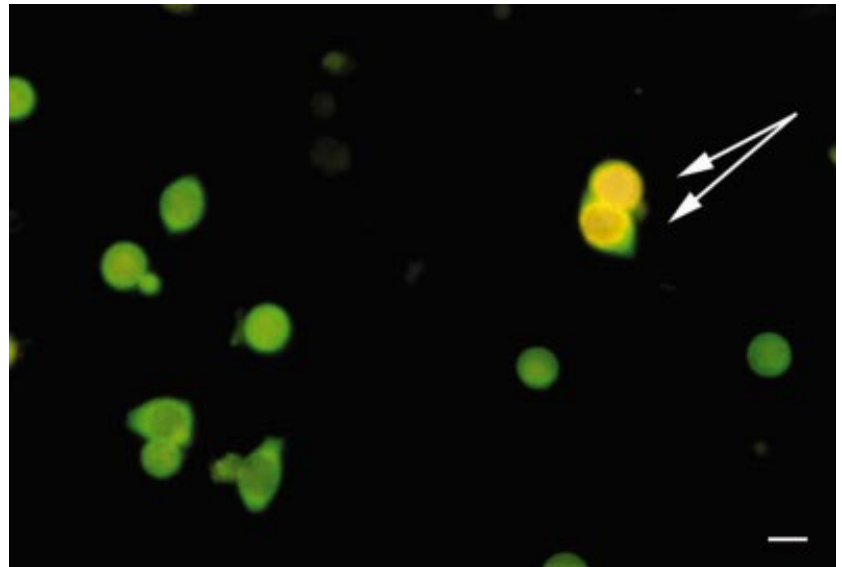

Fig. 4. Co-immunolabelling for bromodeoxyuridine (BrdU; red fluorescence) and heat shock protein-90 $\alpha$ (Hsp90 $\alpha$; green fluorescence) of mouse spermatogonia cultured for 1 day, showing that only germ cells incorporate BrdU (arrows). Scale bar represents $5 \mu \mathrm{m}$.

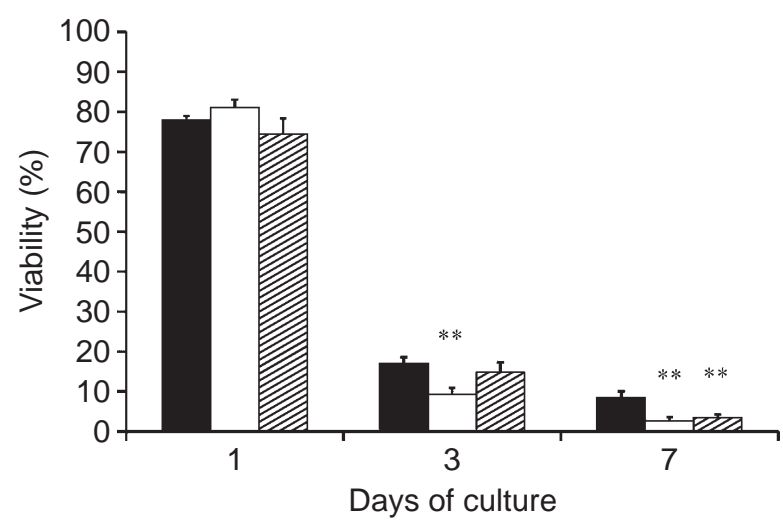

Fig. 5. Comparison of viability of mouse spermatogonia in basic serum-free medium and growth factors $(\mathrm{KSOM}+; \mathbf{\square})$ with medium containing serum. Minimal essential medium (MEM)-fetal calf serum (FCS) ( $\square$ ) and potassium simplex optimized medium (KSOM)-FCS ( are MEM and KSOM, respectively, containing $2.5 \%$ FCS. Data are representative of four experiments. **Significantly different from value for KSOM+ $(P<0.01)$.

\section{Effect of serum on proliferation}

Upon culturing in the presence of serum, the number of cells incorporating BrdU was significantly increased at days 3 and 7 of culture (Fig. $6 ; P<0.05$ and $P<0.01$, respectively). The increase at day 1 was significant in two of the four experiments performed. At this time point the stimulation was restricted to the population of germ cells; all cells containing BrdU were positive for the general germ cell marker Hsp90 $\alpha$ (data not shown). At day 3, FCS had mainly increased the proliferation of germ cells, with a minor fraction of somatic cells dividing. In contrast, at day 7 , the general aspect of the cell culture showed striking differences when compared at day 7 with cells cultured without serum. An extensive layer of flattened epithelial-like cells had formed in which separate cells could be distinguished

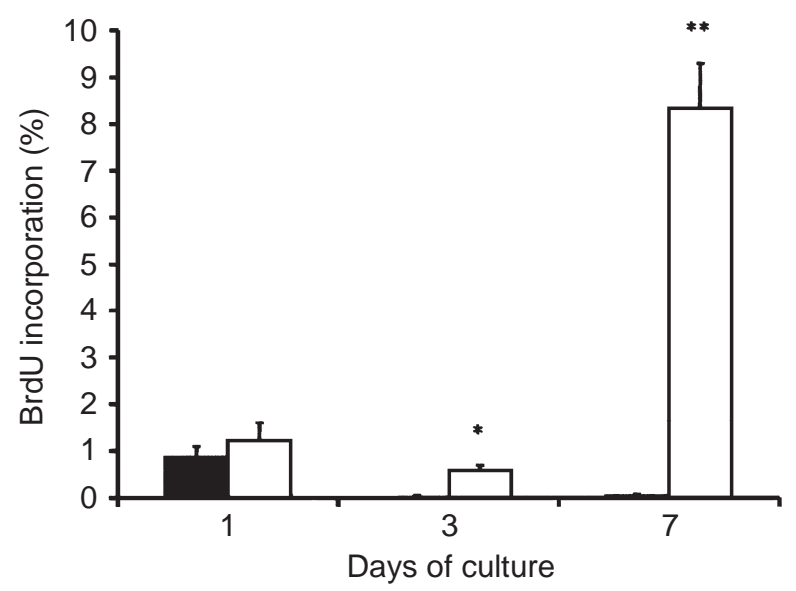

Fig. 6. Increase of overall bromodeoxyuridine (BrdU) incorporation by adult mouse spermatogonia upon culture in basic serumfree medium and growth factors $(\mathrm{KSOM}+; \mathbf{\square})$ or minimal essential medium-fetal calf serum ( $\square$ ). Data are representative of four experiments. Comparisons of incubation with or without serum are expressed per time point $(* P<0.05, * * P<0.01)$.

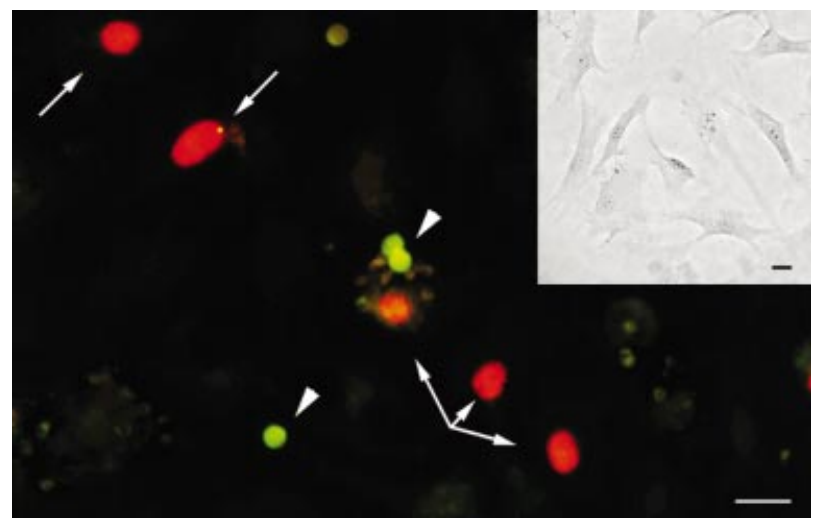

Fig. 7. Bromodeoxyuridine (BrdU) incorporation in mouse spermatogonia after day 7 of culture in the presence of fetal calf serum (FCS). Small round cells positive for heat shock protein- $90 \alpha$ $(H s p 90 \alpha)$ (arrowheads) lie on top of large flattened cells positive for BrdU (arrows). No co-immunolabelling was found. Inset: eosinhaematoxylin staining showing the layer of flattened somatic cells. Scale bars represent $5 \mu \mathrm{m}$.

only by counterstaining with haematoxylin and eosin (Fig. 7 ; inset). These flattened cells were shown to incorporate BrdU (arrows) by immunofluorescence. On top of this layer a few small, round, usually Hsp90 $\alpha$-positive cells (arrowheads) were found, of which none was positive for BrdU.

\section{Viability of prepubertal spermatogonia in KSOM+}

The viability of spermatogonia isolated from prepubertal mice that are 8 days of age was assessed to make a comparison between this commonly used system of cell culture with the current system of culturing adult germ cells. Testes of mice that are 8 days of age commonly contain type $A$ and 


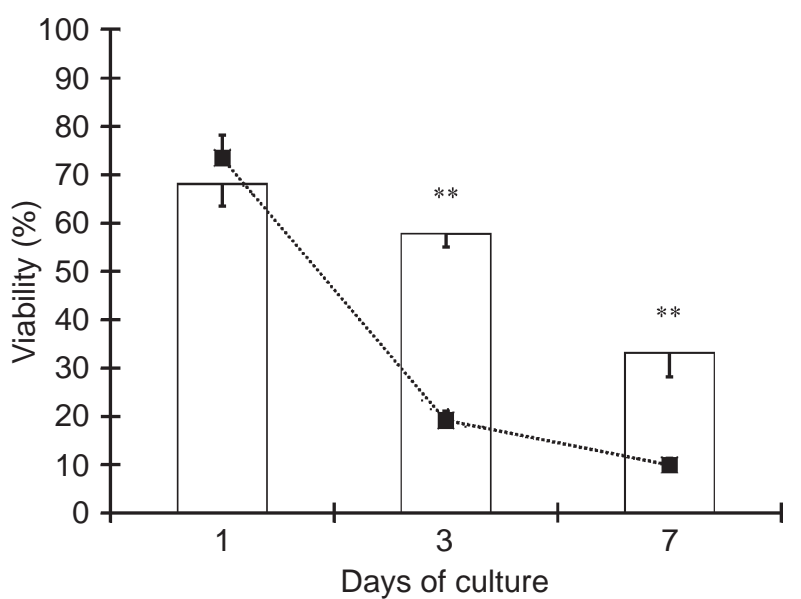

Fig. 8. Viability in serum-free cultures of prepubertal mouse spermatogonia $(\square)$ compared with germ cells derived from vitamin A-deficient (VAD) adult mice ( $\square$ ), cultured under the same circumstances. At day 3 and day 7, viability was significantly higher in the prepubertal cultures compared with the germ cells from VAD adult mice $\left.{ }^{* *} P<0.01\right)$.

B spermatogonia, in a ratio of 6:4 (Bellve et al., 1977). After day 1 of culturing, the viability of the cells was $68 \pm 4(n=5$ experiments), comparable with adult spermatogonia (see also Fig. 2). However, at day 3 of culture, 53\% $(n=5$ experiments) of the cells were still alive, and at day 7 more than one-third of the cells had survived ( $n=4$ experiments) (Fig. 8). Comparison of the mean survival percentages of prepubertal cultures with adult cultures at day 3 and at day 7 , shows that for both time points this difference is significant $(P<0.01)$. Using medium containing serum for prepubertal cultures did not improve viability in this system (data not shown).

\section{Aspects of culture of prepubertal germ cells}

Labelling of germ cells for $\mathrm{Hsp90} \alpha$ demonstrated a heterogeneous morphology, in which cells strongly deviated in size from day 1 of culture onwards (Fig. 9a). Moreover, multinuclear or interconnected cells were frequently observed (Fig. 9a), in contrast to the VAD cultures in which binuclear cells were noted only rarely. These events seemed to increase in frequency during culturing of prepubertal germ cells. Moreover, patches of somatic cells were often seen to support groups of germ cells (Fig. 9b,c).

\section{Proliferation of prepubertal spermatogonia}

Proliferation of prepuberal spermatogonia in culture without serum occurred at days 1, 3 and 7, with a peak at day 3 , at which almost $1 \%$ of the germ cells were incorporating BrdU during the $2.5 \mathrm{~h}$ of exposure (Fig. 10). In these prepubertal cultures, somatic cells proliferated too, albeit mainly at day 3 , where $25 \pm 3 \%$ of all proliferating cells were of somatic origin.

\section{Discussion}

The present study is the first to describe a serum-free culture system of purified adult type A spermatogonia, in which the culture profile is monitored during culture. The viability and proliferation were limited and it was shown that the addition of serum thoroughly changed the composition of the system, which illustrates the importance of monitoring cell behaviour during culturing. Moreover, a comparison between the most commonly used culture system consisting of spermatogonia derived from prepubertal animals, and the current culture of adult spermatogonia, showed that the origin of isolated germ cells has a strong impact on the outcome of culture systems.

In general, culture of primary cells is difficult for a number of reasons. Apart from a decline of viability (Strain, 1994), the original cell characteristics are not easily maintained in vitro (Uhal et al., 1991; Mitaka, 1998; Haselbach et al., 2001) and moreover, cell proliferation is usually minimal or absent (Uhal, et al., 1991; Mitaka, 1998; Kimura et al., 2001). Also, in the culture system used in the present study and in other systems of male germ cell culture, a decrease of viability (Morena et al., 1996; Dirami et al., 1999; Sugiyama et al., 2001) and a low proliferation rate (Maekawa and Nishimune, 1991) were found. Attempts to improve viability of the cultured adult spermatogonia further by adding several growth factors to the basic medium did not yield any clear results. Adding serum to improve viability was found to stimulate the proliferation of somatic cells, a common event in primary culture experiments (Kondo et al., 1991; Mitaka, 1998; Kimura et al., 2001). Although serum is often added to cultures of germ cells (Maekawa and Nishimune, 1991; Morena et al., 1996; Nagano et al., 1998; Sugiyama et al., 2001; van der Wee et al., 2001), apparently it is likely to affect cell content. In similar systems of mixed culture, it will be difficult to separate the direct and indirect effects of serum on spermatogonial behaviour. Moreover, the differentiation of spermatogenic cells in vitro in the presence of serum and somatic co-cultures demonstrated by Tres and Kierszenbaum (1983), and Hue et al. (1998) raises the question to what extent the population of stem cells might become depleted through differentiation.

An important factor determining the viability of the culture system appeared to be the origin of the isolated spermatogonia. Compared with adult spermatogonia isolated from VAD animals, twice as many prepubertal cells, which until now have been of interest in culture systems of spermatogonia, could be kept alive in the present serum-free culture. It could be argued that the adult cells in this system are derived from tissue in a more or less suboptimal state (the lack of vitamin A). This is supported by the recent finding that the stem cell capacity of cell suspensions isolated from VAD mice for recolonization is lower compared with germ cells isolated from hyperthermic testes (McLean et al., 2002). The latter model mimics cryptorchidism, in which spermatogenesis is also limited to the 

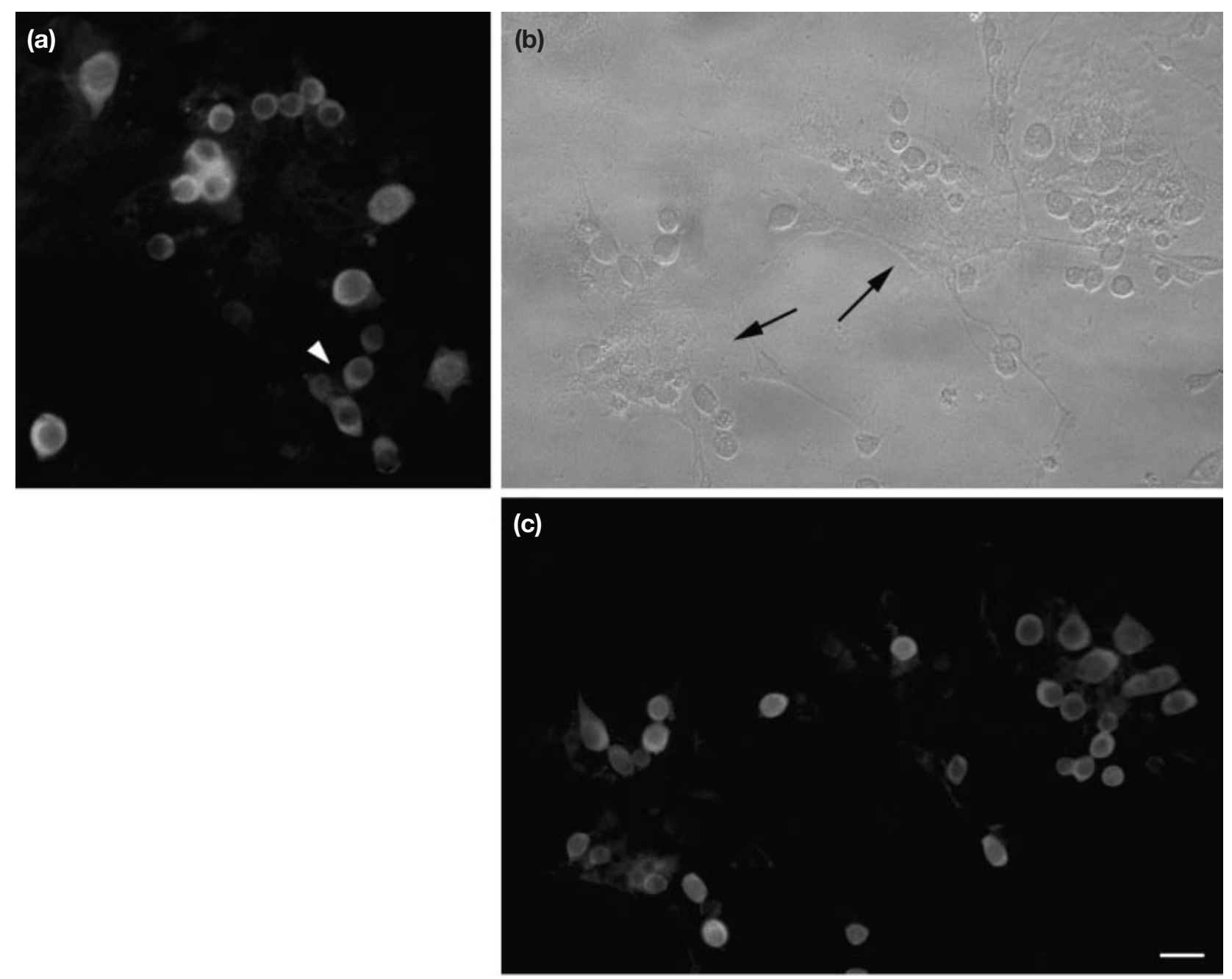

Fig. 9. Morphology of mouse prepubertal germ cell cultures. (a) Throughout culturing, a clear variation in the size of germ cells was observed, with frequent multinuclear or interconnected cells (arrowhead). (b,c) Micrographs of a day 7 culture showing patches of somatic cells (arrows in Hoffman image (b)) underlying the germ cells labelled with anti-Hsp90 $\alpha$ (c). Scale bar represents $5 \mu$ m.

Aal stage (Ito et al., 1997; de Rooij et al., 1999) and colonization efficiency of transplanted germ cells is increased (Shinohara et al., 2000). However, VAD spermatogonia do not exhibit an abnormal degree of apoptosis in vivo (van Pelt and de Rooij, 1990), in contrast to cryptorchid cells (Ito et al., 1997; de Rooij et al., 1999). Moreover, administration of retinoids to VAD animals induces an immediate and sustained resumption of apparently normal spermatogenesis (van Pelt and de Rooij, 1990), indicating that the stem cells in this model are not less viable but merely quiescent. As suggested by McLean et al. (2002), the difficulties of isolated VAD spermatogonia with recolonization may rather be attributed to a lack of spermatogonial expression of proteins needed for differentiation, induced by Sertoli cells in response to retinoid resupplementation.

A plausible explanation for the difference in currently found culture outcome could lie in the heterogeneity of

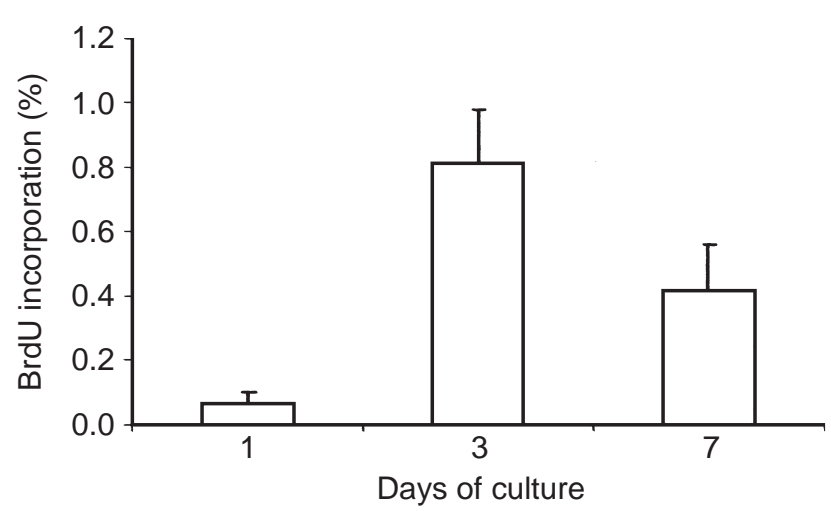

Fig. 10. Bromodeoxyuridine (BrdU) incorporation in prepubertal mouse cell cultures. Proliferation of germ cells is expressed as the percentage of heat shock protein-90 $\alpha$ ( $\mathrm{Hsp} 90 \alpha)$-positive cells that co-labelled for BrdU. 
suspensions of prepubertal germ cells. Instead of only As, $\mathrm{Ap}$ and Aal, present in cell suspensions isolated from VAD animals, prepubertal cell suspensions contain up to type B spermatogonia (Bellve et al., 1977). In the present study this heterogeneity was reflected in the strong variation in the size of germ cells, as reported by van der Wee et al (2001) upon isolation from prepubertal cells and in the occurrence of multinuclear or interconnected germ cells. Differentiating cells, as present in the prepubertal cultures, might be more viable and thus may be responsible for the difference in viability as noted between the two culture models. Another reason for this difference could lie in the characteristics of somatic cells contaminating both culture systems in small fractions. In contrast to the adult culture system, somatic cells in the prepubertal culture system were able to proliferate. This finding indicates that somatic cells contaminating prepubertal suspensions have different properties, as compared with the adult somatic cells, which could include a higher capacity for germ cell support.

Using serum in culture systems introduces a major unknown variable in experimental conditions. Growth factors and other proteins present in serum may inhibit or mask the effects of separately added substances, thus hampering identification of relevant factors and mechanisms in growth and differentiation. Moreover, adding an unidentified mix of components may have unpredictable and undesirable effects, such as the proliferation of contaminating cells found in the present study. Here the use of the current serum-free culture medium seems to provide a benefit over previously mentioned mixtures. Taking the day 3 time point as a reference, Sugiyama et al. (2001) found a viability of not more than approximately $30 \%$ for prepubertal mouse germ cells, even when using feeder layers, and Dirami et al. (1999) reported about 45\% for prepubertal boar cells. Thus the actual percentage of $58 \%$ for prepubertal mouse germ cells in the present study seems to represent a moderate to distinct improvement. Additional refinement by adjusting the growth factor concentrations might further enhance viability.

Relatively successful maintenance of germ cells in vitro, in terms of longevity and even differentiation, has been achieved by culturing fragments of testis or isolated germ cells supported by feeder cells (Tres and Kierszenbaum, 1983; Nagano et al., 1998; Lee et al., 2001; van der Wee et al., 2001; Sousa et al., 2002). However, a defined culture system is required to distinguish between the direct and indirect effects of experimental variation on spermatogonial behaviour. In addition, for clinical applications, the use of supporting cell lines, usually of animal origin or generated by genetic modification, will be precluded, although their conditioned media might be used (Sousa et al., 2002). Optimization of the culture of germ cells in defined medium could be achieved by several approaches. The use of synthetic sera (van der Wee et al., 2001; Sousa et al., 2002) or the identification of relevant growth factors (Dirami et al., 1999) and hormones and their subsequent addition to the culture medium at appropriate concentrations might greatly improve viability or proliferation of spermatogonia, as already established for the culture of hematopoietic progenitors (Simmons and Haylock, 1995) and stem cells (von Kalle et al., 1998). In addition, alteration of the physical aspects of cell culture could be effective, as for example lowering oxygen tension proved beneficial for the maintenance of hematopoietic stem cells (Ivanovic et al., 2002). Subsequent assessment of the outcome of these modifications can be evaluated by transplantation and subsequent evaluation of the amount of recolonization. However, in the long term, biochemical markers of spermatogonial cells will be more efficient in this respect and thus efforts should be also devoted to this aspect of germ cell research.

In conclusion, maintenance of spermatogonia in vitro from adult VAD mice is possible to a limited extent. The addition of serum may improve proliferation, but could be disadvantageous in the long term. Moreover, both in terms of viability and proliferation, the maintenance of prepubertal spermatogonia in vitro is more feasible. The use of well-defined culture conditions for culturing early germ cells is needed for many purposes and merits further studies.

Gratitude is expressed towards René M. C. Scriwanek, Marc A. van Peski and Frits Kindt for their expert assistance with photography. This work was supported by the National Institute of Health.

\section{References}

Bellve AR, Cavicchia JC, Millette CF, O'Brien DA, Bhatnagar YM and Dym M (1977) Spermatogenic cells of the prepuberal mouse. Isolation and morphological characterization Journal of Cell Biology 74 68-85

de Rooij DG, Okabe $\mathbf{M}$ and Nishimune $\mathbf{M}$ (1999) Arrest of spermatogonial differentiation in $j s d / j s d, S / 17 H / S / 17 H$ and cryptorchid mice Biology of Reproduction 61 842-847

Dirami G, Ravindranath N, Pursel V and Dym M (1999) Effects of stem cell factor and granulocyte macrophage-colony stimulating factor on survival of porcine type A spermatogonia cultured in KSOM Biology of Reproduction 61 225-230

Dym M, Jia MC, Dirami G, Price JM, Rabin SJ, Mocchetti I and Ravindranath N (1995) Expression of c-kit receptor and its autophosphorylation in immature rat type A spermatogonia Biology of Reproduction 52 8-19

Emery DW, Sachs DH and LeGuern C (1996) Culture and characterization of hematopoietic progenitor cells from miniature swine Experimental Hematology 24 927-935

Erbach GT, Lawitts JA, Papaioannou VE and Biggers JD (1994) Differential growth of the mouse preimplantation embryo in chemically defined media Biology of Reproduction 50 1027-1033

Haselbach M, Wegener J, Decker S, Engelbertz C and Galla H-J (2001) Porcine choroid plexus epithelial cells in culture: regulation of barrier properties and transport processes Microscopic Research Techniques 52 137-152

Huckins C (1971) The spermatogonial stem cell population in adult rats. I. Their morphology, proliferation and maturation Anatomical Records $169533-557$

Hue D, Staub C, Perrard-Sapori MH, Weiss $M$, Nicolle JC, Vigier $M$ and Durand $\mathbf{P}$ (1998) Meiotic differentiation of germinal cells in three-week cultures of whole cell population from rat seminiferous tubules Biology of Reproduction 59 379-387

Ito K, Tanemura K, Gotoh H, Kurohmaru M and Hayashi Y (1997) Apoptosis-like cell death in experimentally-induced cryptorchidism in adult mice Journal of Veterinary and Medical Science 59 353-359 
Ivanovic Z, Belloc F, Faucher J-L, Cipolleschi M-G, Praloran V and Dello Sbarba P (2002) Hypoxia maintains and interleukin-3 reduces the precolony-forming cell potential of dividing CD34+ murine bone marrow cells Experimental Hematology 30 67-73

Kimura T, van Keymeulen A, Golstein J, Fusco A, Dumont JE and Roger PP (2001) Regulation of thyroid cell proliferation by TSH and other factors: a critical evaluation of in vitro models Endocrine Reviews 22 631-656

Kluin PM, Kramer MF and de Rooij DG (1982) Spermatogenesis in the immature mouse proceeds faster than in the adult International Journal Andrology 5 282-294

Kondo M, Finkbeiner WE and Widdicombe JH (1991) Simple technique for culture of highly differentiated cells from dog tracheal epithelium American Journal of Physiology 261 L106-L117

Lee D, Kaproth MT and Parks JE (2001) In vitro production of haploid germ cells from fresh or frozen-thawed testicular cells of neonatal bulls Biology of Reproduction 65 873-878

Lee S (1990) Expression of HSP86 in male germ cells Molecular and Cellular Biology $103239-3242$

McLean DJ, Russell LD and Griswold MD (2002) Biological activity and enrichment of spermatogonial stem cells in vitamin A-deficient and hyperthermia-exposed testes from mice based on colonization following germ cell transplantation Biology of Reproduction 66 1374-1379

Maekawa M and Nishimune Y (1991) In-vitro proliferation of germ cells and supporting cells in the neonatal mouse testis Cell and Tissue Research $265551-554$

Manova K, Nocka K, Besmer P and Bachvarova RF (1990) Gonadal expression of c-kit encoded at the $\mathrm{W}$ locus of the mouse Development 110 1057-1069

Mitaka T (1998) The current status of primary hepatocyte culture International Journal of Experimental Pathology 79 393-409

Morena AR, Boitani C, Pesce M, De Felici M and Stefanini M (1996) Isolation of highly purified type A spermatogonia from prepubertal rat testis Journal of Andrology 17 708-717

Nagano M, Avarbock MR, Leonida EB, Brinster CJ and Brinster RL (1998) Culture of mouse spermatogonial stem cells Tissue and Cell 30 389-397

Oakberg EF (1971) Spermatogonial stem-cell renewal in the mouse Anatomical Records 169 515-531

Sandlow JI, Feng HL, Cohen MB and Sandra A (1996) Expression of C-KIT and its ligand, stem cell factor, in normal and subfertile human testicular tissue Journal of Andrology 17 403-408

Schrans-Stassen BHGJ, van de Kant HJG, de Rooij DG and van Pelt AMM (1999) Differential expression of c-kit in mouse undifferentiated and differentiating type A spermatogonia Endocrinology $1405894-5900$

Shinohara T, Avarbock MR and Brinster RL (2000) Functional analysis of spermatogonial stem cells in Steel and cryptorchid infertile mouse models Developmental Biology 220 401-411
Simmons PJ and Haylock DN (1995) Use of hematopoietic growth factors for in vivo expansion of precursor cell populations Current Opinions in Hematology 2 189-195

Sousa M, Cremades N, Alves C, Silva J and Barros A (2002) Developmental potential of human spermatogenic cells co-cultured with Sertoli cells Human Reproduction 17 161-172

Strain AJ (1994) Isolated hepatocytes: use in experimental and clinical hepatology Gut 35 433-436

Sugiyama N, Obinata M and Matsui Y (2001) BCL-2 inhibits apoptosis of spermatogonia and growth of spermatogenic stem cells in a cell-intrinsic manner Molecular Reproduction and Development 58 30-38

Tegelenbosch RA and de Rooij DG (1993) A quantitative study of spermatogonial multiplication and stem cell renewal in the $\mathrm{C} 3 \mathrm{H} / 101 \mathrm{~F} 1$ hybrid mouse Mutatation Research 290 193-200

Tres LL and Kierszenbaum AL (1983) Viability of rat spermatogenic cells in vitro is facilitated by their coculture with Sertoli cells in serum-free hormone-supplemented medium Proceedings National Academy of Sciences of the USA 80 3377-3381

Tres LL and Kierszenbaum AL (1999) Cell death patterns of the rat spermatogonial cell progeny induced by Sertoli cell geometric changes and Fas (CD95) agonist Developmental Dynamics 214 361-371

Uhal BD, Flowers KM and Rannels ED (1991) Type II pneumocytes in vitro: problems and future directions American Journal of Physiology Supplement 261 110-117

van der Wee K, Johnson EW, Dirami G, Dym M and Hofmann MC (2001) Immunomagnetic isolation and long term culture of mouse type A spermatogonia Journal of Andrology 22 696-704

van Haaster LH and de Rooij DG (1993) Spermatogenesis is accelerated in the immature Djungarian and Chinese hamster and rat Biology of Reproduction 49 1229-1235

van Pelt AMM and de Rooij DG (1990) Synchronization of the seminiferous epithelium after vitamin A replacement in vitamin A-deficient mice Biology of Reproduction 43 363-367

van Pelt AMM, van Dissel-Emiliani FMF, Gaemers IC, van der Burg MJ, Tanke HJ and de Rooij DG (1995) Characteristics of A spermatogonia and preleptotene spermatocytes in the vitamin A-deficient rat testis Biology of Reproduction 53 570-578

von Kalle C, Glimm H, Schulz G, Mertelsmann R and Henschler R (1998) New developments in hematopoietic stem cell expansion Current Opinion in Hematology 5 79-86

Received 18 June 2002.

First decision 29 August 2002.

Revised manuscript received 2 September 2002.

Accepted 2 September 2002. 